\begin{tabular}{|cc|}
\hline BARBEQUE & GRILLING \\
GLOWING & EMBER \\
ETHYLENE & ACETYLENE \\
ANALYSIS & GC - MS \\
EXPOSURE & HAZARD \\
\hline
\end{tabular}

Open access revised manuscript version of The Science of the total environment 303 (2003) 215-220 Link to publisher: doi:10.1016/50048-9697(02)00403-5

\title{
Benzene emitted from glowing charcoal
}

Maria Olsson and Göran Petersson

Benzene relative to other volatile hydrocarbons was studied for domestic wood burning and burning of wood pellets 


\title{
Benzene emitted from glowing charcoal
}

\author{
Maria Olsson, Göran Petersson* \\ Department of Chemical Environmental Science, Chalmers University of Technology, \\ SE-41296 Göteborg, Sweden
}

\begin{abstract}
Benzene was assessed as the predominant aromatic compound emitted from glowing charcoal and firewood ember. Concentrations above charcoal for grilling exceeded $10 \mathrm{mg} \mathrm{m}^{-3}$ at a 5\% carbon dioxide level. A charcoal with a high carbon content released less benzene. Glowing wood pellets emitted less benzene than glowing firewood remainders.

The emissions of ethene and propene relative to benzene were low for commercial charcoals and wood pellets ember, but high for firewood ember. The proportions of methylbenzene and naphthalene from charcoals were typically only $10 \%$ relative to benzene, and those of benzofuran, dibenzofuran and benzonitrile were typically below 5\%. The PAH indicator phenanthrene was below the $1 \%$ level. Adsorbent sampling and GC-MS was used for assessing all the aromatic compounds.

Earlier studies of charcoal emissions have focused on carbon monoxide, PAH and dioxins. It is concluded that the carcinogenic benzene may be an even more serious health hazard to be considered by exposure-decreasing measures.
\end{abstract}

Keywords: grill, barbeque, ember, combustion; hydrocarbons, exposure 


\section{Introduction}

Charcoal is extensively used for the grilling of food, causing widespread human exposure to emitted compounds. Firewood embers are similar to glowing charcoal. Flaming wood burning is followed by glowing combustion for a similar period of time. Emissions from charcoal combustion are therefore also of great interest with respect to wood burning.

Earlier studies of charcoal emissions have focused on polycyclic aromatic compounds, although PAH emissions from charcoal are much smaller than from other biomass fuels (Larsson et al., 1983; Dyremark et al., 1995). On the other hand, the PAH content is higher in grilled food than in food heated by non-burning methods (Kazerouni et al., 2001; Chen and Liu, 1997). Emissions of toxic dioxins (PCDF/PCDD) are very small from charcoal (Schatowitz et al., 1994).

In a recent study, glowing embers from softwood fuel pellets were shown to emit benzene as the major aromatic compound (Olsson et al., 2002). This study of charcoal was therefore initiated to elucidate emissions of benzene relative to other released gases. Benzene requires dedicated analytical methods and has not been included in earlier studies of emissions from charcoal.

\section{Experimental}

\subsection{Charcoal and wood fuels}

Charcoal (Swedish): Made in Sweden from hardwood (aspen, birch and alder) by Skogens $\mathrm{Kol} \mathrm{AB}$, SIS-labelled, min $83 \%$ carbon, max $3 \%$ ash, $31 \mathrm{~kJ} / \mathrm{g}, 0.3 \mathrm{~g}$ $\mathrm{cm}^{-3}, 6-8$ pieces, totally $20-40 \mathrm{~g}$

Charcoal (Polish): Made in Poland from hardwood, variable quality, DIN- and FSClabelled, $0.4 \mathrm{~g} \mathrm{~cm}^{-3}, 4-6$ pieces, totally $40-60 \mathrm{~g}$ 
Charcoal briquettes: Made in Poland from hardwood, imported by Skandivaror, SIS- and FSC-labelled, $\min 65 \%$ carbon, $\max 15 \%$ ash, $29 \mathrm{~kJ} / \mathrm{g}, 1.0 \mathrm{~g} \mathrm{~cm}^{-3}, 1$ piece, totally $30 \mathrm{~g}$

Wood pellets: $\quad$ Made in Sweden from softwood sawdust by AB Forssjö Bruk, 20 pieces, totally $15-20 \mathrm{~g}$

Firewood: $\quad$ Dry Swedish birchwood, 3 pieces, totally 30-50 g

The charcoal samples were heated with a butane burner until the surfaces were glowing. After flaming burning on a steel net, the remainders of pellets and wood pieces were heated further and left in a uniform glowing state. Before sampling, a pot (3 1) was placed upside down over the glowing materials to increase the concentrations of emitted compounds. Three parallel samples were taken after $10 \mathrm{~s}$ through the bottom hole of the pot, using an adsorbent cartridge and two gas-tight syringes.

\subsection{Analyses of adsorbent samples by GC-MS}

Samples: $\quad$ Approximately $1 \mathrm{ml}$ withdrawn during $20 \mathrm{~s}$ using an air sampling pump

Adsorbent cartridge: Injector glass liner filled with $0.1 \mathrm{~g}$ of Tenax TA, 60-80 mesh

Gas chromatograph: Varian 3800 with $\mathrm{He}$ as carrier gas, $1 \mathrm{ml} \mathrm{min} \mathrm{mi}^{-1}$

Desorption: $\quad$ Thermal, in the injector at $220^{\circ} \mathrm{C}$, with the carrier gas

Column: $\quad 30 \mathrm{~m} \times 0.25 \mathrm{~mm}$ i.d. FSOT

Stationary phase: $\quad$ Cyanopropylphenylsilicone, $\operatorname{Rtx} 1701,0.25 \mu \mathrm{m}$ phase layer

Oven temperature: $\quad$ Increased $10^{\circ} \mathrm{C} \min ^{-1}\left(-50^{\circ} \mathrm{C}\right.$ to $\left.50^{\circ} \mathrm{C}\right)$ and $5^{\circ} \mathrm{C} \min ^{-1}\left(50^{\circ} \mathrm{C}\right.$ to $\left.250^{\circ} \mathrm{C}\right)$

Mass spectrometer: Varian Saturn 2000 , ion trap $\left(120^{\circ} \mathrm{C}\right), \mathrm{EI}$ ionisation $(70 \mathrm{eV})$

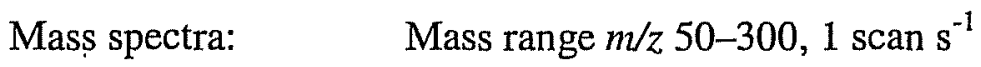

Proportions: Determined from peak areas in the total ion current chromatograms

Absolute response: Estimated using reference gases with benzene and methylbenzene 
Identifications: $\quad$ By comparisons with previous studies and with NIST library support

Further data: $\quad$ Olsson et al., 2002

\subsection{Analyses of gas syringe samples by gas chromatography}

Column, CO: $\quad$ Molecular sieve $13 \mathrm{X}, 80^{\circ} \mathrm{C}, \mathrm{He}, 25 \mathrm{ml} \mathrm{min}^{-1}$

Column, $\mathrm{CO}_{2}$ : $\quad$ HayeSep $\mathrm{Q}, 80^{\circ} \mathrm{C}, \mathrm{He}, 25 \mathrm{ml} \mathrm{min}^{-1}$

Injection, $\mathrm{CO} / \mathrm{CO}_{2}: \quad$ Gas sampling valves, $190 \mu \mathrm{l}(\mathrm{CO})$ and $290 \mu \mathrm{l}\left(\mathrm{CO}_{2}\right)$

Detection, $\mathrm{CO} / \mathrm{CO}_{2}: \quad$ Thermal conductivity, $200^{\circ} \mathrm{C}, 150 \mathrm{~mA}$

Column, $\mathrm{HC}: \quad$ PLOT, $\mathrm{Al}_{2} \mathrm{O}_{3} / \mathrm{KCl}, 50 \mathrm{~m} \times 0.32 \mathrm{~mm}$ i.d., $0-200^{\circ} \mathrm{C}$

Injection, $\mathrm{HC}: \quad$ Gas sampling valve, $3.23 \mathrm{ml}$

Detection, $\mathrm{HC}: \quad \mathrm{FD}, \mathrm{He}$ carrier gas, $20 \mathrm{ml} \mathrm{N} \mathrm{min}^{-1}$ make-up

Further data, HC: $\quad$ Barrefors and Petersson, 1995

\section{Results and discussion}

\subsection{Benzene and minor aromatic compounds from charcoal}

The chromatogram in Fig. 1 illustrates the strong predominance of benzene compared with other aromatic compounds emitted from glowing charcoal. Although the benzene peak goes off scale twice, only minor other peaks appear in the total ion current chromatogram. Nevertheless, all the depicted compounds could be reliably assessed by selective ion monitoring of their predominant molecular ions. The late-eluting minor phenanthrene was also assessed using its molecular ion ( $\mathrm{m} / \mathrm{z}$ 178). The aromatic compounds elute in order of increasing molecular weight, except for benzonitrile $(\mathrm{m} / \mathrm{z}$ 103) with increased retention due to its polarity.

In Table 1, GC-MS results are compared for emissions from three types of commercial charcoal for grilling and for emissions from glowing remainders of softwood pellets and dry birchwood. All weight proportions are given relative to the predominant benzene. Small 


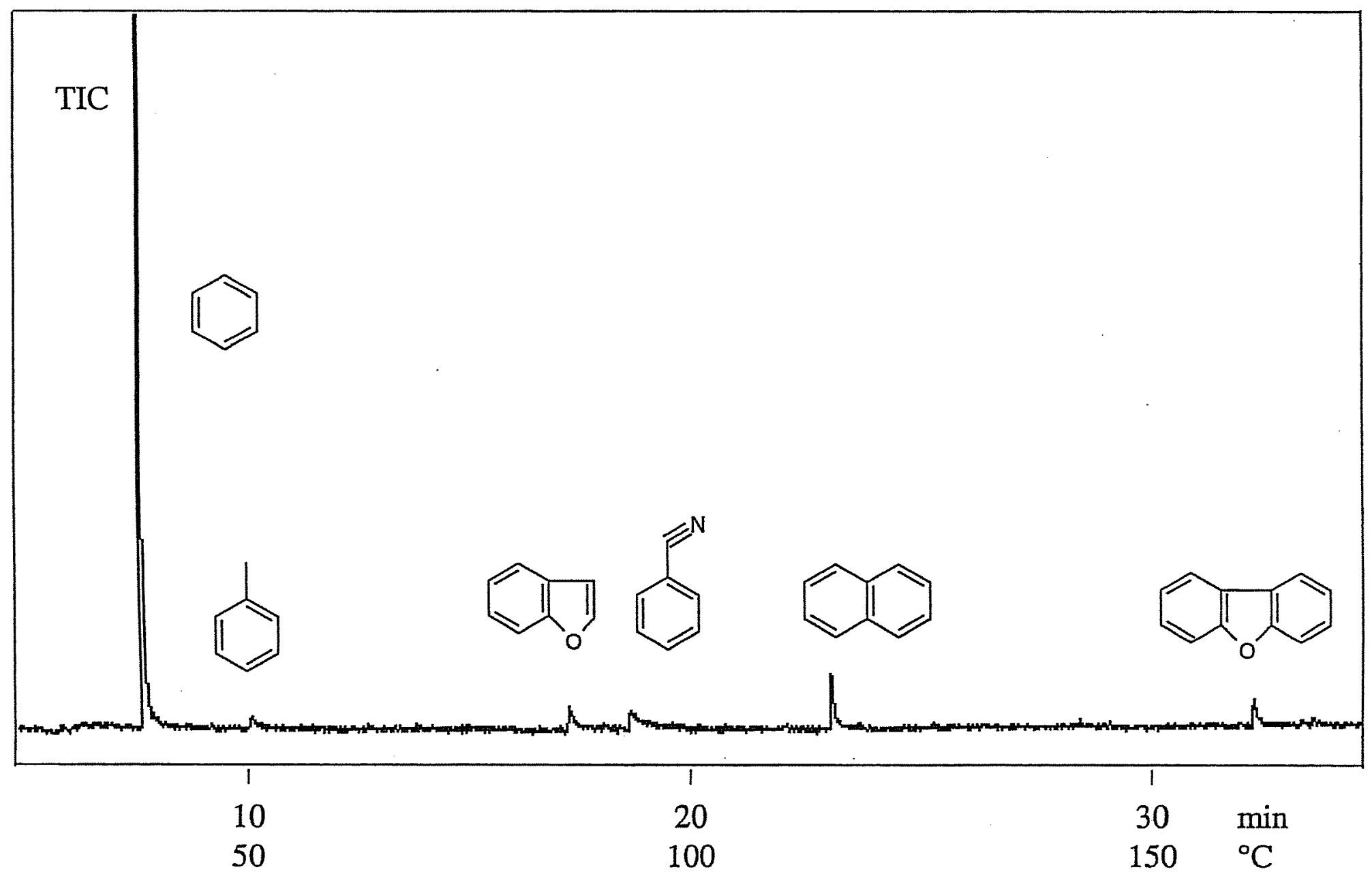

Figure 1 Benzene and minor aromatic compounds released from glowing Swedish charcoal for grilling. Total ion current (TIC) chromatogram with structure formulas of assessed compounds. 
Table 1

Benzene and other aromatic compounds in smoke from glowing charcoal. Average weight proportions relative to benzene (index 100)

\begin{tabular}{|c|c|c|c|c|c|}
\hline & $\begin{array}{l}\text { Charcoal } \\
\text { Hardwood } \\
\text { Sweden } \\
5 \text { samples } \\
\end{array}$ & $\begin{array}{l}\text { Charcoal } \\
\text { Hardwood } \\
\text { Poland } \\
\text { 4 samples } \\
\end{array}$ & $\begin{array}{c}\text { Charcoal } \\
\text { briquettes } \\
\text { Hardwood } \\
\text { Poland } \\
2 \text { samples } \\
\end{array}$ & $\begin{array}{c}\text { Pellets ember } \\
\text { Softwood } \\
\text { Sweden } \\
2 \text { samples } \\
\end{array}$ & $\begin{array}{c}\text { Firewood ember } \\
\text { Birchwood } \\
\text { Sweden } \\
2 \text { samples } \\
\end{array}$ \\
\hline Benzene & 100 & 100 & 100 & 100 & 100 \\
\hline Methylbenzene & $2.9 \pm 2.0$ & $8.5 \pm 7.5$ & 13 & 6.7 & 52 \\
\hline Naphthalene & $5.3 \pm 1.1$ & $6.9 \pm 4.2$ & 12 & 8.6 & 9.6 \\
\hline Phenanthrene & $0.2 \pm 0.2$ & $0.2 \pm 0.1$ & 0.2 & 0.6 & 0.7 \\
\hline Biphenyl & $0.2 \pm 0.1$ & $0.4 \pm 0.2$ & 0.7 & 0.3 & 1.7 \\
\hline Benzofuran & $3.6 \pm 1.9$ & $2.1 \pm 0.9$ & 1.1 & 5.4 & 13 \\
\hline Dibenzofuran & $2.8 \pm 2.1$ & $1.6 \pm 1.1$ & 1.2 & 5.2 & 5.6 \\
\hline Benzonitrile & $1.3 \pm 1.2$ & $5.5 \pm 5.1$ & 4.2 & 4.4 & 9.3 \\
\hline
\end{tabular}


sampling volumes permitted quantitative adsorption of all aromatic compounds, including benzene, on the Tenax adsorption cartridges (Olsson et al., 2002). The analytical approach also permitted assessment of benzofuran ( $\mathrm{m} / \mathrm{z} 118)$ and dibenzofuran $(\mathrm{m} / \mathrm{z} 168)$ which are seldom reported in PAH studies. The identifications and the quantitative determinations were in accordance with previous studies (Olsson et al., 2002). The results reflect the sum of gaseous and particulate contributions (Kjällstrand and Petersson, 2001).

The quantitative proportions are similar for the three different brands of charcoal. The high carbon content of the Swedish charcoal may explain the observed low proportions of methylbenzene and benzonitrile. The density was lowest for the Swedish charcoal and highest for the compressed charcoal briquettes which may cause other observed differences. The structural and heat transport properties of charcoal produced from solid firewood have been described (Larfeldt et al., 2000). Softwood pellets are made from compressed sawdust and are increasingly used for residential heating (Olsson et al., 2002). The results for pellets embers are similar to those for charcoal. Evidently, flaming burning efficiently converts the porous pellets to remainders with charcoal characteristics.

\subsection{Combustion characteristics}

The spectacular generation of the carcinogenic benzene from charcoal called for a comparison with the formation of commonly assessed combustion products. In Table 2, recorded proportions are given for $\mathrm{CO}_{2}, \mathrm{CO}, \mathrm{CH}_{4}$, ethene, propene, ethyne and benzene. Carbon dioxide and carbon monoxide were determined from the same gas syringe sample by gas chromatography with thermal conductivity detection. The five hydrocarbons were assessed from another gas syringe sample by gas chromatography on an aluminium oxide column with flame ionisation detection (Barrefors and Petersson, 1995). The concentrations of the hydrocarbons are reported as ppmC (ppm $\times$ number of carbon atoms in the compound). 
Table 2

Concentrations of prominent carbon-containing compounds in smoke from glowing charcoal, reflecting the quantitative proportions of carbon incorporated into the species.

\begin{tabular}{lccccc}
\hline & Charcoal, Sweden & Charcoal, Poland & Charcoal briquettes & Pellets ember & Firewood ember \\
\hline Carbon dioxide (\%) & 6.2 & 6.9 & 5.4 & 2.7 & 5.3 \\
Carbon monoxide (\%) & 0.9 & 1.3 & 1.5 & 0.4 & 1.2 \\
Methane (\%) & 0.006 & 0.11 & 0.05 & 0.001 & 0.07 \\
Ethene (ppmC) & 1 & 13 & 7 & 0.5 & 66 \\
Propene (ppmC) & 0.07 & 2 & 3 & 0.05 & 35 \\
Ethyne (ppmC) & 14 & 13 & 6 & 3 & 9 \\
Benzene (ppmC) & 5 & 46 & 43 & 2 & 23 \\
\hline
\end{tabular}


The proportions given in Table 2 therefore reflect the relative numbers of carbon atoms released as the specific tabulated compounds.

The benzene concentrations measured above the Polish charcoal exceeded $40 \mathrm{ppmC}$ or $20 \mathrm{mg} \mathrm{m}^{-3}$, meaning that almost every thousandth carbon atom released was incorporated into benzene. For the Swedish charcoal and the pellets embers, the formation of benzene relative to carbon dioxide was an order of magnitude lower. This may be explained by a higher proportion of carbon in the fuels and a more efficient combustion of the more porous materials. The results for glowing pellets conform to previous studies of pyrolysis of wood pellets (Olsson et al., 2002).

Prominent proportions of benzene and ethyne with a high $\mathrm{C} / \mathrm{H}$ ratio characterise the hydrocarbon emissions from charcoal. This is probably explained by the high carbon content, exceeding $80 \%$ in the Swedish charcoal studied. The results also demonstrated a low formation of methane from charcoal with a high carbon content. The proportions of ethene and propene were higher for the charcoal and briquettes from Poland with their lower carbon content.

The results for glowing remainders of solid firewood were quite different, although the final phase of flaming burning was assisted by a butane torch to avoid unburnt wood. The proportions of ethene and propene relative to benzene were much higher. The proportion of methylbenzene relative to benzene was also much higher than for charcoal. The proportions of benzene and ethyne were similar to those for charcoal, but it should be noted that benzene and ethyne are thermally unusually stable unsaturated hydrocarbons. Their relative proportions of total unsaturated volatile hydrocarbons from wood fuels increase with the combustion temperature (Barrefors and Petersson, 1995). 


\subsection{Human exposure}

The results demonstrate that as much as $0.1 \%$ of the carbon released from charcoal can be emitted as benzene. This causes concentrations of benzene exceeding $10 \mathrm{mg} \mathrm{m}^{-3}$ above the bed of charcoal at a $5 \%$ carbon dioxide and $1 \%$ carbon monoxide level. An efficient way to decrease personal exposure should be to avoid inhaling grill gases near to the charcoal bed. Indoor grilling with charcoal requires efficient ventilation. The results also indicate that choosing a charcoal with high carbon content efficiently decreases benzene emissions.

The benzene emissions from firewood embers were found to be as high as from commercial charcoal. Genotoxic health hazards from ethene and propene (Törnqvist and Ehrenberg, 1994) are more severe for glowing firewood because of the higher emissions. Glowing birchwood has previously been shown to emit a wide range of hazardous $\mathrm{C}_{4}-\mathrm{C}_{5}$ unsaturated hydrocarbons, including the carcinogenic 1,3-butadiene (Barrefors and Petersson, 1995). These hydrocarbons were almost absent in charcoal emissions. The results therefore indicate more severe health hazards from glowing birchwood.

Benzene exposure from grilling over charcoal and from wood burning adds to exposure from other sources. Private cars and tobacco smoke are major outdoor and indoor sources of benzene exposure (Barrefors and Petersson, 1993). The abundance of these sources makes it difficult to identify contributions from grilling to ambient concentrations of volatile hydrocarbons even in grill restaurants (Mugica et al., 2001). Nevertheless, specific benzene exposure near to charcoal grills is concluded to be significant. Uptake of benzene in fatty foods grilled over charcoal may cause additional exposure with food intake. Naphthalene has been assessed in charcoal-grilled duck (Chen and Liu, 1997).

Several other chemical health hazards due to emissions from charcoal have been discussed. The results in Table 2 illustrate the well known very high proportions of carbon monoxide from charcoal burning. Occupational hazards due to exposure to carbon monoxide have been demonstrated for grill workers (Madani et al., 1992), suggesting proportionately 
elevated benzene exposure. The proportions of specific carcinogenic polycyclic aromatic hydrocarbons emitted from grill charcoal have been related to phenanthrene as the major PAH (Dyremark et al., 1995). The PAH emissions are comparatively small. Much higher concentration ratios between phenanthrene and benzene have been observed in smoke from residential wood burning (Kjällstrand and Petersson, 2001).

It is concluded that benzene is a major health hazard from charcoal during grilling and from firewood embers, although several additional chemical hazards must be considered.

\section{Acknowledgement}

The financial support of the Swedish Energy Agency is gratefully acknowledged.

\section{References}

Barrefors G, Petersson G. Assessment of ambient volatile hydrocarbons from tobacco smoke and from vehicle emissions. J Chromatogr 1993; 643: 71-76.

Barrefors G, Petersson G. Volatile hydrocarbons from domestic wood burning. Chemosphere 1995; 30: 1551-1556.

Chen $\mathrm{B}$, Lin $\mathrm{Y}$. Formation of polycyclic aromatic hydrocarbons during processing of duck meat. J Agric Food Chem 1997; 45: 1394-1403.

Dyremark A, Westerholm R, Övervik E, Gustavsson J-Å. Polycyclic aromatic hydrocarbon (PAH) emissions from charcoal grilling. Atmos Environ 1995; 29: 1553-1558.

Kazerouni N, Sinha R, Hsu C-H, Greenberg A, Rothman N. Analysis of 200 food items for benzo[a]pyrene and estimation of its intake in an epidemiologic study. Food Chem Toxicol 2002; 39: 423-436.

Kjällstrand J, Petersson G. Phenols and aromatic hydrocarbons in chimney emissions from traditional and modern residential wood burning. Environ Technol 2001; 22: 391-395. 
Larfeldt J, Leckner B, Melaaen M C. Modelling and measurements of heat transfer in charcoal from pyrolysis of large wood particles. Biomass and Bioenergy 2000; 18: 507514.

Larsson B, Sahlberg G, Eriksson A, Busk L. Polycyclic aromatic hydrocarbons in grilled food. J Agric Food Chem 1983; 31: 867-873.

Madani I, Khalfan S, Khalfan H, Jidah J, Aladin N. Occupational exposure to carbon monoxide during charcoal meat grilling. Sci Total Environ 1992; 14: 141-147.

Mugica V, Vega E, Chow J, Reyes E, Sánchez G, Arriaga J, Egami R, Watson J. Speciated non-methane organic compounds emissions from food cooking in Mexico. Atmos Environ 2001; 35: 1729-1734.

Olsson M, Kjällstrand J, Petersson G. Oxidative pyrolysis of integral softwood pellets. J Anal Appl Pyrolysis 2002; in press.

Schatowitz B, Brandt G, Gafner F, Schlumpf E, Bühler R, Hasler P, Nussbaumer T. Dioxin emissions from wood combustion. Chemosphere 1994; 29: 2005-2013.

Törnqvist M, Ehrenberg L. On cancer risk estimation of urban air pollution. Environ Health Perspect 1994; 102 (Suppl 4): 173-182. 